\title{
Scopolamine Induces Disruption of Latent Inhibition which is Prevented by Antipsychotic Drugs and an Acetylcholinesterase Inhibitor
}

\author{
Segev Barak' and Ina Weiner*,' \\ 'Department of Psychology, Tel-Aviv University, Tel-Aviv, Israel
}

\begin{abstract}
The fact that muscarinic antagonists may evoke a psychotic state ('antimuscarinic psychosis'), along with findings of cholinergic alterations in schizophrenia, have kindled an interest in the involvement of the cholinergic system in this disorder. Latent inhibition (LI) is a crossspecies phenomenon manifested as a poorer conditioning of a stimulus seen when the stage of conditioning is preceded by a stage of repeated nonreinforced pre-exposure to that stimulus, and is considered to index the capacity to ignore irrelevant stimuli. Amphetamine-induced LI disruption and its reversal by antipsychotic drugs (APDs) is a well-established model of positive symptoms of schizophrenia. Here, we tested whether the muscarinic antagonist scopolamine would disrupt $\mathrm{LI}$ and whether such disruption would be reversed by APDs and by the acetylcholinesterase inhibitor physostigmine. The results showed that scopolamine at doses of 0.15 and $0.5 \mathrm{mg} / \mathrm{kg}$ disrupted $\mathrm{LI}$, and that this effect was due to the action of the drug in the pre-exposure stage, suggesting a role of muscarinic transmission in attentional processes underlying LI. Both the typical and the atypical APDs, haloperidol and clozapine, reversed scopolamine-induced LI disruption when given in conditioning or in both stages, but not in pre-exposure, indicating that the mechanism of antipsychotic action in this model is independent of the mechanism of action of the propsychotic drug. Scopolamine-induced LI disruption was reversed by physostigmine $(0.05$ and $0.15 \mathrm{mg} / \mathrm{kg})$, which was ineffective in reversing amphetamine-induced LI disruption, pointing to distinct mechanisms underlying $\mathrm{LI}$ disruption by these two propsychotic drugs. The latter was further supported by the finding that unlike amphetamine, the LI-disrupting doses of scopolamine did not affect activity levels. We propose scopolamine-induced LI disruption as a model of cholinergic-related positive symptoms in schizophrenia.
\end{abstract}

Neuropsychopharmacology (2007) 32, 989-999. doi:I0.I038/sj.npp. I 30I208; published online I3 September 2006

Keywords: latent inhibition; scopolamine; antipsychotic drugs; physostigmine; acetylcholine; schizophrenia

\section{INTRODUCTION}

'Anticholinergic' muscarinic antagonists such as scopolamine or atropine may evoke a psychotic state termed 'anticholinergic syndrome' or 'antimuscarinic psychosis'. Noteworthy, in comparison to the dopamine (DA)-releasing psychotomimetic amphetamine, which induces psychosis characterized by hallucinations and delusions (Snyder, 1973), antimuscarinic-induced psychosis includes in addition disorganized thinking, attentional impairments, and delirium, characteristics of endogenous schizophrenia (Clarke et al, 2004; Fisher, 1991; Holland, 1992; Marchlewski, 1994; Mego et al, 1988; Minzenberg et al, 2004; Perry and Perry, 1995; Perry et al, 1978; Wilkinson, 1987; Yeomans, 1995). Antimuscarinic psychosis can be alleviated by

\footnotetext{
*Correspondence: Dr I Weiner, Department of Psychology, Tel-Aviv University, Ramat-Aviv, Tel-Aviv 69978, Israel, Tel: 97236408993 , Fax: 9723 6409547, E-mail: weiner@post.tau.ac.il

Received 8 May 2006; accepted 8 August 2006

Online publication: 15 August 2006 at http://www.acnp.org/citations/ Npp081506060300/default.pdf
}

antipsychotic drugs (APDs) (Gopel et al, 2002; Perry et al, 1978) as well as by acetylcholinesterase (AChE) inhibitors (Brown et al, 2004; Gopel et al, 2002; Granacher and Baldessarini, 1975; Nogue et al, 1991; Perry et al, 1978). Conversely, muscarinic antagonists used to reduce extrapyramidal side effects associated with APDs (Tandon, 1999) have been reported to exacerbate schizophrenia symptoms and to interfere with the therapeutic effects of APDs (Johnstone et al, 1983; Lo and Tsai, 1996; Singh and Kay, 1975, 1979; Tandon et al, 1990). These findings, taken together with postmortem and neuroimaging findings of cholinergic alterations in the brains of schizophrenia patients (eg Crook et al, 2001; Dean et al, 1996; Garcia-Rill et al, 1995; Karson et al, 1991; Raedler et al, 2003; Zavitsanou et al, 2005), have led to a growing interest in the involvement of the cholinergic system in this disorder (eg Hyde and Crook, 2001; Sarter et al, 2005; Tandon et al, 1992; Weiner et al, 2004; Yeomans, 1995). The focus on the cholinergic system has been reinforced by the increasingly acknowledged need for improved treatments of cognitive deficits in schizophrenia (eg Bymaster et al, 2002; Friedman, 2004). 
Consistent with findings in humans, systemic administration of nonspecific muscarinic antagonists, such as atropine or scopolamine, has been shown to induce psychotic-like effects in several animal models of schizophrenia, including locomotor hyperactivity (Mathur et al, 1997; Shannon and Peters, 1990; Sipos et al, 1999), stereotypy (Mathur et al, 1997), and disruption of prepulse inhibition (PPI) (Jones et al, 2005; Jones and Shannon, 2000a, b; Ukai et al, 2004; Wu et al, 1993), and these effects were reversed by cholinomimetic drugs, such as the AChE inhibitor physostigmine (Jones and Shannon, 2000b; Shannon and Peters, 1990), as well as APDs (Jones et al, 2005; Shannon and Peters, 1990).

To date, there has not been a systematic investigation of the effects of muscarinic antagonists on latent inhibition (LI), a well-established model of schizophrenia. LI is a cross-species phenomenon manifested as a poorer conditioning to a stimulus that is seen when the stage of conditioning is preceded by a stage of repeated nonreinforced pre-exposure to that stimulus. LI is commonly considered to index the ability to ignore stimuli that predicted no significant consequences in the past and has been used extensively to model cognitive impairments in schizophrenia (Weiner, 1990, 2000, 2003). It has been suggested that LI stems from the reduced attention to, or the associability of, the pre-exposed (PE) stimulus, which reduces the effectiveness with which it enters into an association with reinforcement (Lubow et al, 1981; Lubow, 1989). An alternative explanation posits that the acquisition of an association between the PE CS and the absence of a significant consequence during preexposure interferes with the subsequent expression (Gray et al, 1995a; Weiner, 1990, 2003) or retrieval (Bouton, 1993) of the CS-reinforcement association. LI is disrupted in rats and mice by amphetamine (eg Killcross and Robbins, 1993; Meyer et al, 2004; Moran et al, 1996; Weiner et al, 1984, 1988) and this is paralleled by disrupted LI in amphetamine-treated normal humans (Gray et al, 1992b; Salgado et al, 2000; Swerdlow et al, 2003; Thornton et al, 1996) and in acute schizophrenia patients (Baruch et al, 1988; Gray et al, 1992a, 1995b; Rascle et al, 2001; but also see Swerdlow et al, 2005). The LI model is further validated by its sensitivity to APDs, which reverse amphetamine-induced disruption of LI and potentiate the phenomenon under conditions that do not suffice to yield it in no-drug controls, such as low number of pre-exposures (Gosselin et al, 1996; Shadach et al, 1999; Warburton et al, 1994; Weiner et al, 1996).

Pharmacological studies of LI using cholinergic compounds in rats and humans used primarily nicotinic agents and have yielded inconsistent findings (Della Casa et al, 1999; Gould et al, 2001; Gray et al, 1997; Joseph et al, 1993; Rochford et al, 1996; Thornton et al, 1996). To the best of our knowledge, few studies testing the effects of muscarinic manipulations on LI have been published to date. Moore et al (1976) found that scopolamine injected in both preexposure and conditioning did not affect LI in rabbits. However, both systemic (Carlton and Vogel, 1965) and intra-insular cortex (Naor and Dudai, 1996) injection of scopolamine confined to the pre-exposure stage disrupted LI in rats. Finally, LI was shown to be enhanced in M5 mutant mice (Wang et al, 2004).
The present study tested whether scopolamine would disrupt LI and whether such disruption would be reversed by APDs. As scopolamine is known to induce memory and learning deficits, which could mask its effect on LI, we used low doses of scopolamine previously shown to spare associative learning (Anagnostaras et al, 1999). In addition, because the effects of propsychotic and antipsychotic compounds on LI depend on whether they are administered in pre-exposure or conditioning (Weiner, 2003), we sought to determine the stage at which scopolamine and APDs act to produce LI disruption and restoration, respectively. Specifically, Experiment 1 tested the effects of $0.15,0.5$, and $1 \mathrm{mg} / \mathrm{kg}$ scopolamine given in both stages on LI, and Experiment 2 tested at what stage of the LI procedure scopolamine acts to produce LI disruption. Experiments 3 and 4 tested the effects of the typical APD haloperidol and the atypical APD clozapine, respectively, on scopolamineinduced LI disruption and at which stage these drugs acted. In addition to APDs, we tested in Experiment 5 the effects of physostigmine on scopolamine-induced LI disruption. Finally, Experiment 6 tested the capacity of the low doses of scopolamine found to disrupt LI to produce locomotor hyperactivity. For purposes of comparison, amphetamine was included in Experiments 1, 5, and 6.

\section{MATERIALS AND METHODS}

\section{Subjects}

Male Wistar rats (Tel Aviv University Medical School, Tel Aviv), 3-4 months old and weighing $280-460 \mathrm{~g}$, were housed four to a cage under reversed cycle lighting (lights on: 1900$0700 \mathrm{~h}$ ) with ad lib food and water except for the duration of the LI experiments (see below). All experimental protocols conformed to the guidelines of the Institutional Animal Care and Use Committee of Tel Aviv University, Israel, and to the guidelines of the $\mathrm{NIH}$ (animal welfare assurance number A5010-01, expires on November 30, 2006). All efforts were made to minimize the number of animals used and their suffering.

\section{Apparatus and Procedure}

LI. LI was measured in a thirst-motivated, conditioned emotional response (CER) procedure by comparing the suppression of drinking to a tone previously paired with a foot shock in rats that received nonreinforced exposure to the tone prior to conditioning (PE) and in rats for whom the tone was novel (non-pre-exposed (NPE)).

Rats were tested in Campden Instruments rodent test chambers (model 410) with a retractable bottle. When the bottle was not present, the hole was covered by a metal lid. Licks were detected by a Campden Instruments drinkometer (model 435). The PE to-be-conditioned stimulus was a $10 \mathrm{~s}, 80 \mathrm{~dB}, 2.8 \mathrm{kHz}$ tone produced by a Sonalert module (model SC 628). Shock was supplied through the floor by a Campden Instruments shock generator (model 521/C) and shock scrambler (model 521/S) set at $0.5 \mathrm{~mA}$ and $1 \mathrm{~s}$ duration. Equipment programming and data recording were computer controlled.

Prior to the beginning of each LI experiment, rats were handled for about $2 \mathrm{~min}$ daily for 5 days. A $23 \mathrm{~h}$ water 
restriction schedule was initiated simultaneously with handling and continued throughout the experiment. On the next 5 days, rats were trained to drink in the experimental chamber for $20 \mathrm{~min}$ during the 1 st day and for $15 \mathrm{~min} /$ day during each of the next 4 days. Water in the test apparatus was given in addition to the daily ration of $1 \mathrm{~h}$ given in the home cages. The LI procedure was conducted on days 11-14 and consisted of the following stages:

Pre-exposure (day 11): With the bottle removed, the PE rats received 40 tone presentations with an inter-stimulus interval of $40 \mathrm{~s}$. The NPE rats were confined to the chamber for an identical period of time without receiving the tone.

Conditioning (day 12): With the bottle removed, each rat received two tone-shock pairings given 5 min apart. Shock immediately followed tone termination. The first toneshock pairing was given $5 \mathrm{~min}$ after the start of the session. After the last pairing, rats were left in the experimental chamber for an additional $5 \mathrm{~min}$.

Rebaseline (day 13): Rats were given a 15 min drinking session as in initial training. Data of rats that failed to complete 600 licks were dropped from the analysis.

Test (day 14): Each rat was placed in the chamber and allowed to drink from the bottle. When the rat completed 75 licks, the tone was presented for $5 \mathrm{~min}$. The following times were recorded: time to first lick, time to complete licks 1-50, time to complete licks 51-75 (before tone onset), and time to complete licks 76-100 (after tone onset). Times to complete licks 76-100 were submitted to logarithmic transformation to allow parametric analysis of variance. Longer log times indicate stronger suppression of drinking. LI is defined as significantly shorter log times to complete licks $76-100$ of the PE compared to NPE rats.

Spontaneous and drug-induced activity. Activity was measured in plastic chambers $(46 \times 57 \times 37 \mathrm{~cm})$, covered by $50 \times 50 \mathrm{~cm}$ clear Perspex lids, located in a darkened room. A Coulbourn Instruments infrared sensor unit was installed in the center of a front wall $22 \mathrm{~cm}$ from the side walls, and $12 \mathrm{~cm}$ above the grid floor. The sensor was protected by a wire fence measuring $10 \times 13 \times 6 \mathrm{~cm}$ to prevent animals' access. Blind areas of the sensor (the two corners of the triangles adjacent to the sensor, measuring $17 \times 17 \times 25$ ) were blocked by two clear Perspex walls with dimensions of $25 \times 57 \mathrm{~cm}$. The movements detected by the sensor were transmitted through a Coulbourn Instruments eight-channel infrared motion interface to a Coulbourn Instruments infrared motion activity monitor controller/ analyzer. Rats were individually placed in the activity chambers and allowed $30 \mathrm{~min}$ of free exploration (spontaneous activity), after which they were returned to their home cage, injected with the appropriate drug and replaced into the chamber for an additional $60 \mathrm{~min}$ (drug-induced activity). The pre- and post-drug duration of movements for each animal were recorded in 6 min blocks. Data recording was computer controlled.

\section{Drugs}

All drugs were administered intraperitoneally in a volume of $1 \mathrm{ml} / \mathrm{kg}$. Scopolamine $\mathrm{HBr}$ (Sigma, Israel) was diluted in saline and administered at doses of $0.15,0.5$, or $1 \mathrm{mg} / \mathrm{kg}$. Haloperidol, prepared from an ampoule containing $5 \mathrm{mg}$ haloperidol in $1 \mathrm{ml}$ solvent containing $6 \mathrm{mg}$ lactic acid (Johnson \& Johnson, Belgium) and diluted with saline, was administered at a dose of $0.1 \mathrm{mg} / \mathrm{kg}$. Clozapine (Novartis, Switzerland), dissolved in $1 \mathrm{~N}$ acetic acid $(1.5 \mathrm{ml} / 10 \mathrm{mg})$ and diluted with saline, was administered at a dose of $10 \mathrm{mg} / \mathrm{kg}$. Physostigmine (eserine) hemisulfate (Sigma, Israel) was diluted in saline and administered at doses of 0.05 or $0.15 \mathrm{mg} / \mathrm{kg}$. D-amphetamine (Sigma, Israel) was diluted in saline and administered at a dose of $1 \mathrm{mg} / \mathrm{kg}$. The doses of scopolamine were chosen based on studies showing that they did not disrupt tone-shock conditioning (Anagnostaras et al, 1999). The doses of haloperidol, clozapine, and amphetamine were chosen based on our previous LI studies using these drugs (Weiner et al, 1987, 1997, 1996). The doses of physostigmine were chosen based on previous behavioral experiments with this drug (Jones and Shannon, 2000b; Shannon and Peters, 1990). In LI experiments (1-5), all drugs were administered $30 \mathrm{~min}$ prior to pre-exposure and/or conditioning, except for haloperidol, which was administered $60 \mathrm{~min}$ prior to pre-exposure and/or conditioning. No drug controls received the corresponding vehicle.

\section{Data Analysis}

In LI experiments, times to complete licks $50-75$ and mean log times to complete licks 76-100 were analyzed in experiments 1-4 using two-way ANOVA with main factors of pre-exposure $(0,40)$ and treatment (five levels in experiments 1,3 , and 4 , and three levels in experiment 2 ), and in experiment 5 , using a three-way ANOVA with main factors of pre-exposure $(0,40)$, treatment (vehicle, scopolamine, amphetamine), and pretreatment $(0,0.05$, and $0.15 \mathrm{mg} / \mathrm{kg}$ physostigmine). LSD post hoc comparisons were used to assess the difference between the PE and NPE groups within each drug condition. In locomotor activity experiment (experiment 6), duration of movements was analyzed using a $4 \times(3) \times(5)$ ANOVA with main factor of drug and repeated measurements factors of three 30-min periods (1-30 min before injection, 31-60 min after injection, 61-90 min after injection) and five 6-min blocks within each 30 -min period.

\section{Experiment 1: Effects of $0.15,0.5$, or $1 \mathrm{mg} / \mathrm{kg}$ Scopolamine and $1 \mathrm{mg} / \mathrm{kg}$ Amphetamine on LI}

The experiment included 10 experimental groups ( $n$ per group $=11-13)$ in a $2 \times 5$ design with main factors of preexposure $(0,40)$ and treatment (vehicle, $0.15 \mathrm{mg} / \mathrm{kg}$ scopolamine, $0.5 \mathrm{mg} / \mathrm{kg}$ scopolamine, $1 \mathrm{mg} / \mathrm{kg}$ scopolamine, $1 \mathrm{mg} / \mathrm{kg}$ amphetamine). Both drugs were administered prior to the pre-exposure and the conditioning stages.

Results. The 10 experimental groups did not differ in their times to complete licks $51-75$ before tone onset (all $p$ 's $>0.05$; overall mean $A$ period $=6.97 \mathrm{~s}$ ). Figure 1 presents the mean $\log$ times to complete licks 76-100 (after tone onset) of the PE and NPE rats injected with vehicle, $0.15 \mathrm{mg} /$ $\mathrm{kg}$ scopolamine, $0.5 \mathrm{mg} / \mathrm{kg}$ scopolamine, $1 \mathrm{mg} / \mathrm{kg}$ scopolamine, or $1 \mathrm{mg} / \mathrm{kg}$ amphetamine. As can be seen, LI was 


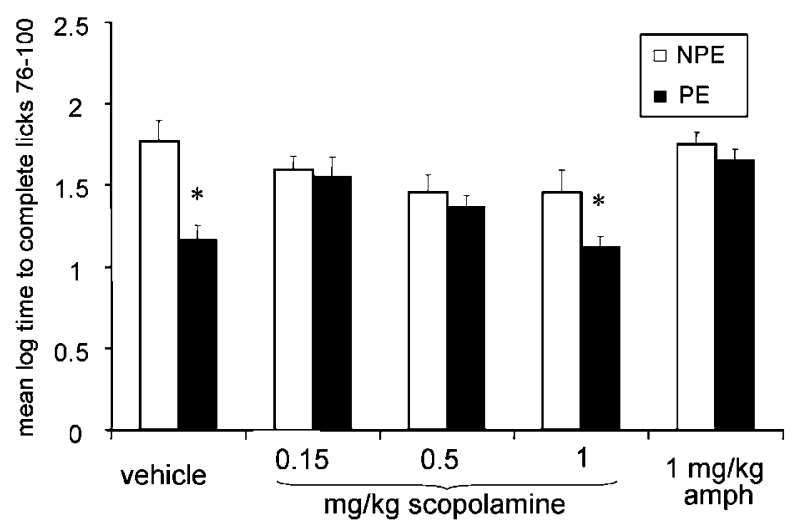

Figure I Effects of scopolamine on LI. Means and standard errors of the log times to complete licks 76-100 (after tone onset) of the pre-exposed (PE) and non-pre-exposed (NPE) rats injected with vehicle, scopolamine $(0.15,0.5, I \mathrm{mg} / \mathrm{kg}$ ), or amphetamine (amph; I mg/ $/ \mathrm{kg}$ ). Asterisk indicates a significant difference between the PE and NPE groups, namely, presence of LI.

present in vehicle-treated rats, but was disrupted by amphetamine as well as by the two lower doses of scopolamine, whereas the highest dose of scopolamine $(1 \mathrm{mg} / \mathrm{kg})$ spared LI. ANOVA yielded significant main effects of pre-exposure $\left(\mathrm{F}_{(1,107)}=14.01, p<0.0005\right)$ and treatment $\left(\mathrm{F}_{(4,107)}=5.17, \quad p<0.001\right)$, and a significant interaction of pre-exposure $\times$ treatment $\left(\mathrm{F}_{(4,107)}=2.98\right.$, $p<0.05)$. Post hoc comparisons revealed a significant difference between the PE and NPE groups, that is, LI, in rats injected with vehicle $(p<0.0001)$, and $1 \mathrm{mg} / \mathrm{kg}$ scopolamine $(p<0.05)$ but not in the other three conditions.

\section{Experiment 2: Effects of $0.15 \mathrm{mg} / \mathrm{kg}$ Scopolamine Injected in PE or Conditioning on LI}

This experiment sought to determine at which stage of the LI procedure scopolamine acted to produce LI disruption. This was of particular interest because previous studies had shown that amphetamine did not disrupt LI when given in the pre-exposure stage alone (Weiner, 2003; Weiner and Feldon, 1997; Weiner et al, 1984, 1988), but disrupted LI if administered in conditioning (Gray et al, 1997; Joseph et al, 2000). The experiment included six experimental groups ( $n$ per group $=7-8$ ) in a $2 \times 3$ design with main factors of pre-exposure $(0,40)$ and treatment (vehicle, scopolamine in pre-exposure, scopolamine in conditioning).

Results. The six experimental groups did not differ in their times to complete licks $51-75$ before tone onset (all $p$ 's $>0.05$; overall mean $A$ period $=6.76 \mathrm{~s}$ ). Figure 2 presents the mean log times to complete licks 76-100 (after tone onset) of the PE and NPE rats injected with vehicle, scopolamine in pre-exposure, or scopolamine in conditioning. As can be seen, LI was present in vehicle-treated rats as well as in rats injected with scopolamine in the conditioning stage alone. In contrast, LI was disrupted following scopolamine administration in the pre-exposure stage alone. ANOVA yielded significant main effects of preexposure $\left(\mathrm{F}_{(1,40)}=20.187, \quad p<0.0001\right)$ and treatment $\left(\mathrm{F}_{(2,40)}=5.46, p<0.05\right)$, and a nearly significant interaction of treatment $\times$ pre-exposure $\left(\mathrm{F}_{(2,40)}=2.704, p=0.079\right)$. Post

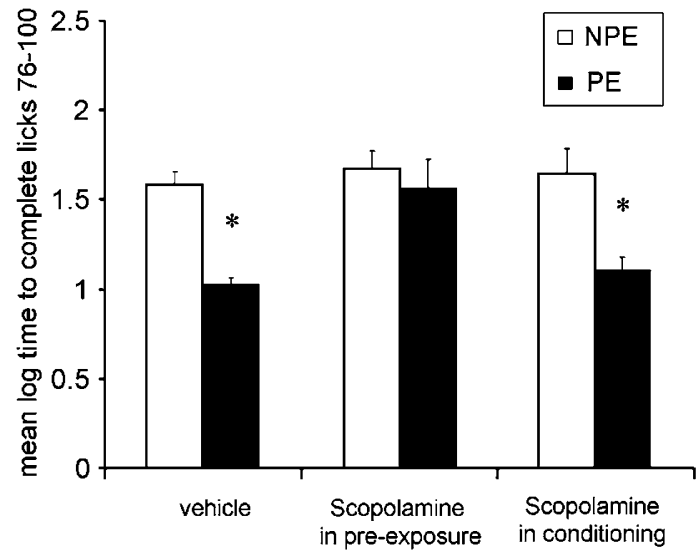

Figure 2 Effects of scopolamine on $\mathrm{LI}$ as a function of stage of administration. Means and standard errors of the log times to complete licks 76-100 (after tone onset) of the pre-exposed (PE) and non-preexposed (NPE) vehicle- or scopolamine $(0.15 \mathrm{mg} / \mathrm{kg})$-injected rats. Scopolamine was injected either in the pre-exposure stage or in the conditioning stage. Asterisk indicates a significant difference between the PE and NPE groups, namely, presence of LI.

hoc comparisons revealed a significant difference between the PE and NPE groups injected with vehicle $(p<0.001)$ and scopolamine in conditioning $(p<0.005)$, but not between those injected with scopolamine in pre-exposure.

\section{Experiments 3 and 4: Effects of Haloperidol and Clozapine on Pre-Exposure-Based Scopolamine-Induced LI Disruption}

As APDs-induced reversal of disrupted LI is owing to their effects in the conditioning stage (Weiner, 2003), experiments 3 and 4 tested whether the same pattern would be seen with scopolamine-induced LI disruption. This was of particular interest given that scopolamine disrupted LI via effects at the pre-exposure stage, thus raising the possibility that APDs would reverse scopolamine-induced LI disruption not at the stage of the LI procedure at which disruption was induced. Scopolamine was injected in the pre-exposure stage. Haloperidol and clozapine (Experiments 3 and 4, respectively) were injected to scopolamine-treated rats in either the pre-exposure stage, the conditioning stage, or in both stages. We did not administer haloperidol and clozapine on their own, because we had extensively characterized the effects of both drugs on LI in the present procedure in our previous studies. Specifically, we have shown that both drugs have no effect on LI when given in conditioning or in both stages, whereas clozapine, but not haloperidol, can disrupt LI when administered in preexposure (Shadach et al, 2000; Weiner, 2003; Weiner et al, 1987, 1997).

\section{Experiment 3: Effects of $0.1 \mathrm{mg} / \mathrm{kg}$ Haloperidol Injected in Pre-Exposure and/or Conditioning on Pre-Exposure-Based Scopolamine-Induced LI Disruption}

The experiment included 10 experimental groups ( $n$ per group $=7-10)$ in a $2 \times 5$ design with main factors of preexposure $(0,40)$ and treatment (vehicle, scopolamine, 
scopolamine + haloperidol in pre-exposure, scopolamine + haloperidol in conditioning, scopolamine + haloperidol in both stages). Data of four rats were dropped from the analysis.

Results. The 10 experimental groups did not differ in their times to complete licks 51-75 before tone onset (all $p$ 's $>0.05$; overall mean $A$ period $=7.65 \mathrm{~s}$ ). Figure 3 presents the mean log times to complete licks 76-100 (after tone onset) of the PE and NPE rats injected with vehicle, scopolamine, scopolamine + haloperidol in pre-exposure, scopolamine + haloperidol in conditioning, or scopolamine + haloperidol in both stages. As can be seen, LI was present in vehicle-treated rats and absent in rats that were treated with scopolamine. Haloperidol restored LI in scopolaminetreated rats when given in both pre-exposure and conditioning as well as if given only in conditioning, but failed to restore LI if given in pre-exposure only. ANOVA yielded a significant main effect of pre-exposure $\left(\mathrm{F}_{(1,76)}=17.29\right.$, $p<0.0001$ ), and a significant interaction of treatment $\times$ preexposure $\left(\mathrm{F}_{(4,76)}=2.69, p<0.05\right)$. Post hoc comparisons revealed a significant difference between the PE and NPE groups injected with vehicle $(p<0.001)$, scopolamine + haloperidol in conditioning $(p<0.001)$, and scopolamine + haloperidol in both stages $(p<0.05)$, but not between PE and NPE groups that received only scopolamine, or scopolamine + haloperidol in pre-exposure.

\section{Experiment 4: Effects of $10 \mathrm{mg} / \mathrm{kg}$ Clozapine Injected in Pre-Exposure and/or Conditioning on Scopolamine-Induced LI Disruption}

The experiment included 10 experimental groups ( $n$ per group $=7-10)$ in a $2 \times 5$ design with main factors of preexposure $(0,40)$ and treatment (vehicle, scopolamine, scopolamine + clozapine in pre-exposure, scopolamine +

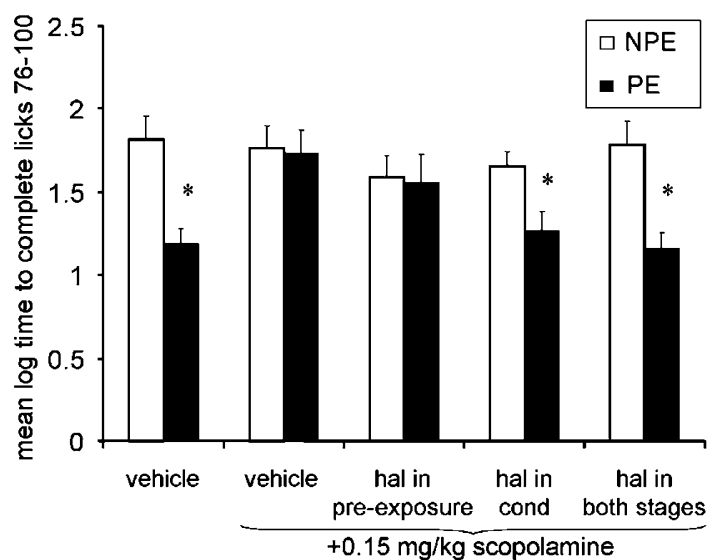

Figure 3 Effects of haloperidol on scopolamine-induced LI disruption as a function of stage of administration. Means and standard errors of the log times to complete licks 76-100 (after tone onset) of the pre-exposed (PE) and non-pre-exposed (NPE) rats in four drug conditions: vehicle, scopolamine $(0.15 \mathrm{mg} / \mathrm{kg}$ ), scopolamine + haloperidol (hal; $0.1 \mathrm{mg} / \mathrm{kg}$ ) in pre-exposure, scopolamine + haloperidol in conditioning, and scopolamine + haloperidol in both stages. Scopolamine was injected in the preexposure stage. Asterisk indicates a significant difference between the PE and NPE groups, namely, presence of LI. clozapine in conditioning, scopolamine + clozapine in both stages). Data of three rats were dropped from the analysis.

Results. The 10 experimental groups did not differ in their times to complete licks 51-75 before tone onset (all $p$ 's $>0.05$; overall mean $A$ period $=7.16 \mathrm{~s}$ ). Figure 4 presents the mean log times to complete licks 76-100 (after tone onset) of the PE and NPE rats injected with vehicle, scopolamine, scopolamine + clozapine in pre-exposure, scopolamine + clozapine in conditioning, or scopolamine + clozapine in both stages. As can be seen, LI was present in vehicle-treated rats and absent in rats treated with scopolamine. Clozapine restored LI in scopolamine-treated rats if given in both pre-exposure and conditioning as well as if given in conditioning only, but failed to restore LI if given in pre-exposure only. ANOVA yielded significant main effects of pre-exposure $\left(\mathrm{F}_{(1,74)}=15.97, p<0.0005\right)$ and treatment $\left(\mathrm{F}_{(4,74)}=5.94, p<0.0005\right)$, and an almost significant interaction of treatment $\times$ pre-exposure $\left(\mathrm{F}_{(4,74)}=2.43, p=0.055\right)$. Post hoc comparisons revealed a significant difference between the PE and NPE groups in rats injected with vehicle $(p<0.005)$, scopolamine + clozapine in conditioning $(p<0.01)$, and scopolamine + clozapine in both stages $(p<0.05)$, but not in rats injected with scopolamine or scopolamine + clozapine in pre-exposure.

\section{Experiment 5: Effects of Physostigmine on Scopolamine- and Amphetamine-Induced LI Disruption}

Because physostigmine increases ACh levels in the synaptic cleft, we expected that it would reverse the effect of scopolamine-induced muscarinic blockade on LI, as has been found for scopolamine-induced PPI disruption and hyperactivity. In addition, because it was reported that physostigmine might act similarly to 'dopaminergic' APDs

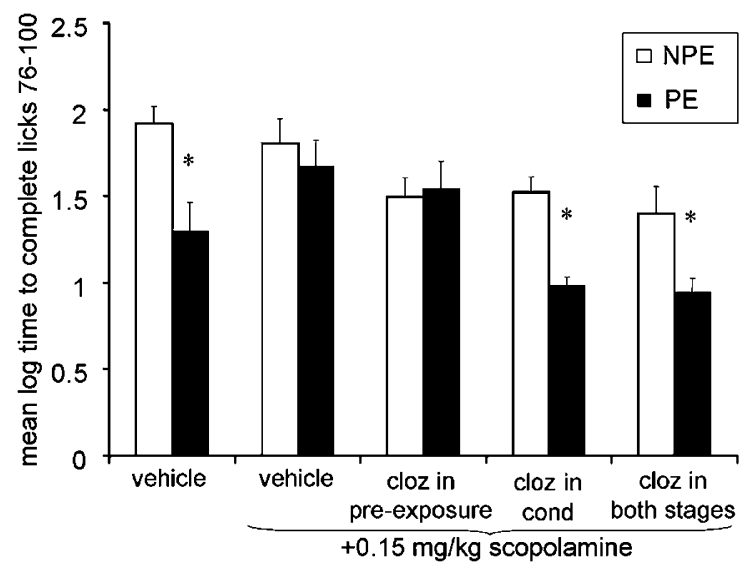

Figure 4 Effects of clozapine on scopolamine-induced LI disruption as a function of stage of administration. Means and standard errors of the log times to complete licks 76-I00 (after tone onset) of the pre-exposed (PE) and non-pre-exposed (NPE) rats in four drug conditions: vehicle, scopolamine $(0.15 \mathrm{mg} / \mathrm{kg}$ ), scopolamine + clozapine (cloz; $10 \mathrm{mg} / \mathrm{kg}$ ) in pre-exposure, scopolamine + clozapine in conditioning, and scopolamine + clozapine in both stages. Scopolamine was injected in the pre-exposure stage. Asterisk indicates a significant difference between the PE and NPE groups, namely, presence of LI. 
(Karan et al, 2000), our interest was to test whether this drug would also reverse amphetamine-induced LI disruption. The experiment included 18 experimental groups $(n$ per group $=7-9)$ in a $2 \times 3 \times 3$ design with main factors of pre-exposure $(0,40)$, treatment (vehicle, scopolamine, amphetamine), and pretreatment $(0,0.05,0.15 \mathrm{mg} / \mathrm{kg}$ physostigmine). Data of three rats were dropped from the analysis.

Results. The 18 experimental groups did not differ in their times to complete licks $51-75$ before tone onset (all $p$ 's $>0.05$; overall mean $A$ period $=6.76 \mathrm{~s}$ ). Figure 5 presents the mean log times to complete licks 76-100 (after tone onset) of the PE and NPE rats in the different experimental groups. As can be seen, LI was present in vehicle-treated rats and in rats injected with physostigmine alone, but was absent in rats that were treated with scopolamine or amphetamine. Physostigmine, at both doses, restored LI in scopolamine-treated rats, but failed to restore LI in amphetamine-treated rats. ANOVA yielded significant main effects of pre-exposure $\left(\mathrm{F}_{(1,119)}=62.85, p<0.0001\right)$, treatment $\left(\mathrm{F}_{(2,119)}=13.55, p<0.0001\right)$, and pretreatment $\left(\mathrm{F}_{(2,119)}=3.71, p<0.05\right)$, and significant interactions of pre-exposure $\times$ treatment $\quad\left(\mathrm{F}_{(2,119)}=9.4, \quad p<0.0005\right) \quad$ and pre-exposure $\times$ treatment $\times$ pretreatment $\quad\left(\mathrm{F}_{(4,119)}=2.52\right.$, $p<0.05)$. Post hoc comparisons revealed a significant difference between the PE and NPE groups in the vehicle, $0.05 \mathrm{mg} / \mathrm{kg}$ physostigmine, scopolamine $+0.05 \mathrm{mg} / \mathrm{kg}$ physostigmine $(p$ 's $<0.0001), 0.15 \mathrm{mg} / \mathrm{kg}$ physostigmine, and scopolamine $+0.15 \mathrm{mg} / \mathrm{kg}$ physostigmine $(p$ 's $<0.005)$ conditions, but not in the scopolamine alone, amphetamine alone, or the two amphetamine + physostigmine conditions.
Experiment 6: Effects of 0.15 and $0.5 \mathrm{mg} / \mathrm{kg}$ Scopolamine and $1 \mathrm{mg} / \mathrm{kg}$ Amphetamine on Locomotor Activity

Drug-induced locomotor hyperactivity is the most widely used animal model of psychosis; accordingly, scopolamine has been shown to increase locomotor activity, but only at doses higher than $0.3 \mathrm{mg} / \mathrm{kg}$ (Mathur et al, 1997; Shannon and Peters, 1990; Sipos et al, 1999). While scopolamine at low doses used here $(0.15$ and $0.5 \mathrm{mg} / \mathrm{kg})$ disrupted LI like amphetamine $(1 \mathrm{mg} / \mathrm{kg}$; Experiment 1$)$, Experiment 5 indicated that these two propsychotic drugs may act via distinct mechanisms. We, therefore, compared the effects of the low doses of scopolamine and amphetamine on locomotor activity. The experiment included four experimental groups ( $n$ per group $=6-7$ )

Results. Figure 6 presents the means and standard errors of duration of movements, in 6 min blocks, before and after vehicle, scopolamine, or amphetamine injection. As can be seen, spontaneous activity levels (first $30 \mathrm{~min}$ period) did not differ among the groups. Following amphetamine injection, there was a dramatic rise in activity level. No such increase was seen in scopolamine-injected rats although the higher dose produced a mild increase in activity. ANOVA yielded significant main effects of drug $\left(\mathrm{F}_{(3,21)}=9.97, \quad p<0.0005\right)$, periods $\left(\mathrm{F}_{(3,42)}=9.32\right.$, $p<0.0005)$, and blocks $\left(\mathrm{F}_{(4,84)}=5.43, p<0.001\right)$ as well as significant interactions of drug $\times$ periods $\left(\mathrm{F}_{(6,42)}=8.6\right.$, $p<0.0001)$, periods $\times$ blocks $\left(\mathrm{F}_{(8,168)}=2.21, p<0.05\right)$, and drug $\times$ period $\times$ blocks $\left(\mathrm{F}_{(24,168)}=3.38, p<0.0001\right)$. Post hoc comparisons indicated that only amphetamine significantly increased duration of movements compared to the vehicle group $(p<0.0001)$.

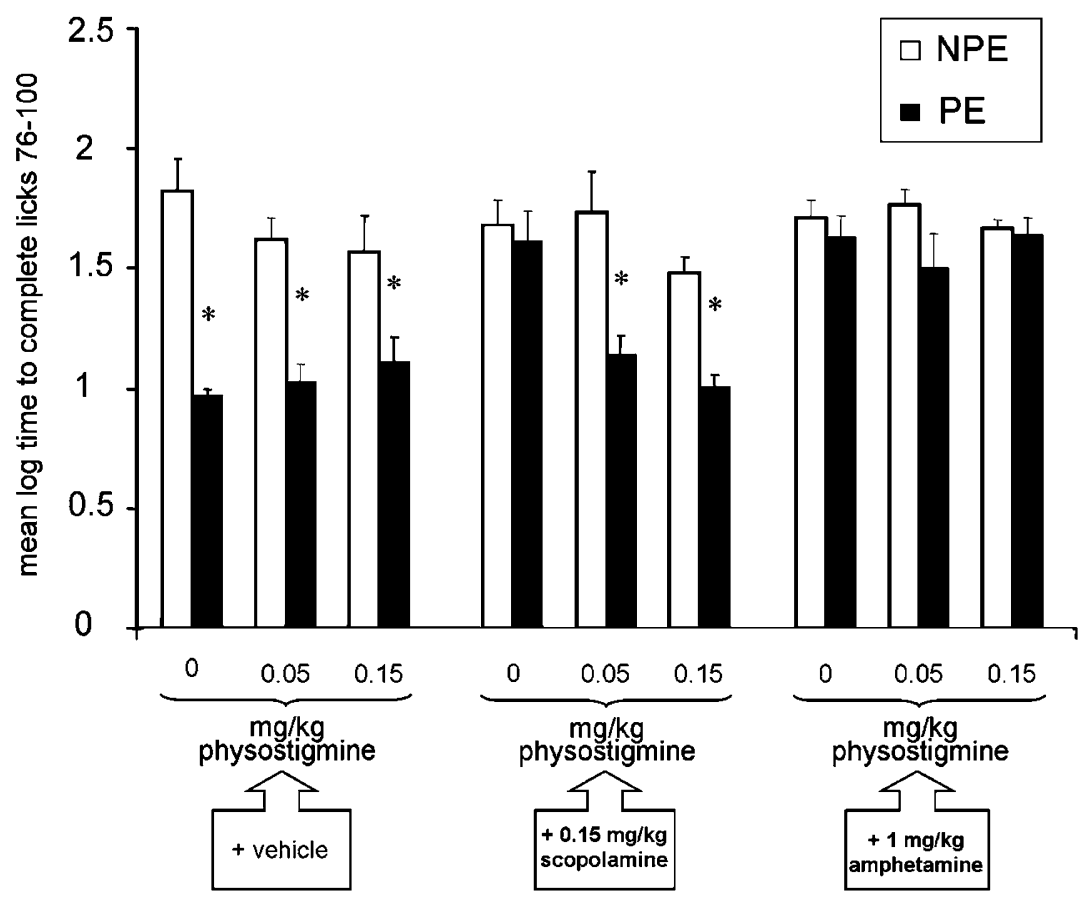

Figure 5 Effects of physostigmine on scopolamine- and amphetamine-induced LI disruption. Means and standard errors of the log times to complete licks 76-100 (after tone onset) of the pre-exposed (PE) and non-pre-exposed (NPE) vehicle-, scopolamine $(0.15 \mathrm{mg} / \mathrm{kg})$-, or amphetamine (I mg/kg)-treated rats, pretreated with physostigmine $(0.05,0.15 \mathrm{mg} / \mathrm{kg})$. Scopolamine was injected in the pre-exposure stage. Amphetamine and physostigmine were injected in both stages. Asterisk indicates a significant difference between the PE and NPE groups, namely, presence of LI. 


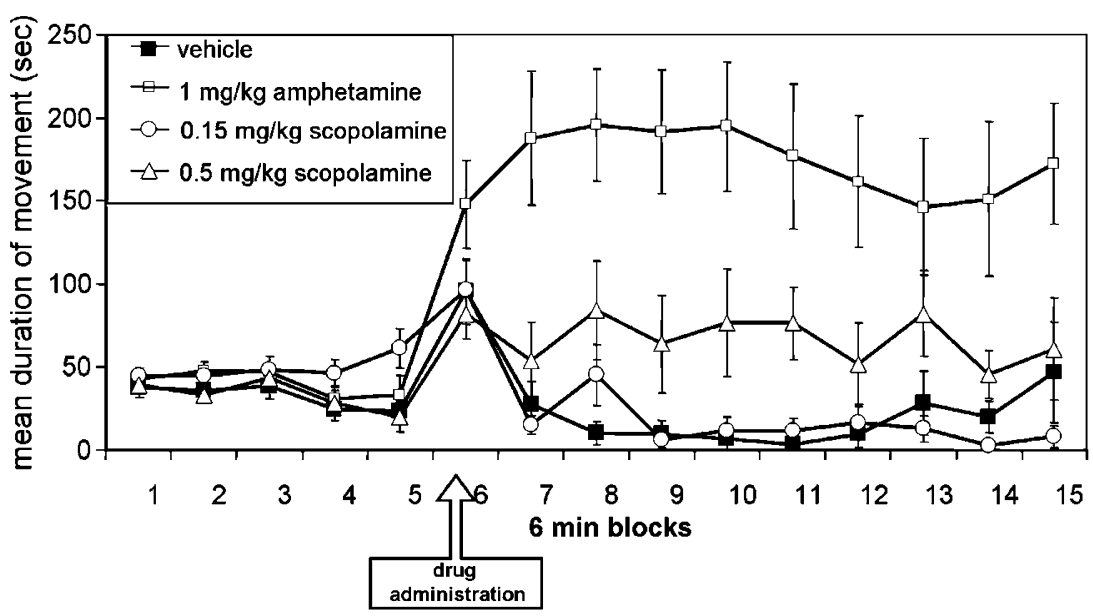

Figure 6 Effects of scopolamine and amphetamine on locomotor activity. Means and standard errors of duration of movements, in 6 min blocks, before (blocks I-5) and after (blocks 6-15) injection of vehicle, I mg/kg amphetamine, $0.15 \mathrm{mg} / \mathrm{kg}$ scopolamine, or $0.5 \mathrm{mg} / \mathrm{kg}$ scopolamine.

\section{DISCUSSION}

The present experiments demonstrated that LI can be abolished by scopolamine, and that this abolition can be reversed by APDs, as well as by the AChE inhibitor, physostigmine. Experiment 1 showed that scopolamine, administered in both pre-exposure and conditioning at doses of 0.15 and $0.5 \mathrm{mg} / \mathrm{kg}$, abolished LI, while sparing LI at a higher dose of $1 \mathrm{mg} / \mathrm{kg}$. These results are consistent with other findings suggesting that lower doses of muscarinic antagonists might be more effective than higher doses in some behavioral procedures. For example, Carnicella et al (2005) showed that the muscarinic antagonist atropine disrupted the degraded contingency effect (retarded conditioning following high probability of US-alone presentations compared to high probability of CS-US presentations) at $5 \mathrm{mg} / \mathrm{kg}$, but not at higher doses. Likewise, Ukai et al (2004) showed that scopolamine attenuated PPI in mice at a dose of $0.3 \mathrm{mg} / \mathrm{kg}$, but not at higher doses. It is not clear why scopolamine loses its efficacy in disrupting LI at higher doses. One possibility is that low and high doses of scopolamine bind to different types of muscarinic receptors, for example, excitatory $v s$ inhibitory. The dose-dependent effects of scopolamine on DA release within the nucleus accumbens (NAC) may be particularly relevant in this respect. Thus, low dose of scopolamine increased NAC DA release, presumably via blockade of M2 inhibitory autoreceptors, whereas at higher doses this effect diminished, presumably due to increased blockade of M1 receptors (Ichikawa et al, 2002b). As LI disruption requires DA release within the NAC (Joseph et al, 2000; Weiner, 2003), this would be expected to occur with low but not high scopolamine doses.

In line with previous results (eg Anagnostaras et al, 1999), scopolamine at doses used here did not impair tone-shock conditioning, as reflected in the fact that suppression levels of scopolamine-treated NPE rats did not differ from those of vehicle-treated NPE rats. In fact, scopolamine-induced LI disruption stemmed exclusively from improved performance of the scopolamine-treated PE groups, which showed levels of suppression similar to those of their NPE counterparts. In other words, scopolamine-treated PE rats behaved as if they were not PE. The latter could stem from at least two sources: (1) scopolamine enhanced fear conditioning selectively in PE rats, or attenuated the retarding effect of stimulus pre-exposure on its subsequent conditioning; in this case, the site of scopolamine action would be the conditioning stage; (2) scopolamine impaired the capacity to learn to ignore the PE stimulus in the preexposure stage. The results of Experiment 2 supported the latter possibility. In this experiment, $0.15 \mathrm{mg} / \mathrm{kg}$ scopolamine disrupted LI if given only before pre-exposure, but not if given only before conditioning. Although this pattern could reflect state dependency, this possibility was ruled out by our finding that the same dose of scopolamine disrupted LI also when given before both stages. Pre-exposure-based LI disruption by scopolamine is consistent with the results of Carlton and Vogel (1965), but contradict those of Moore et al (1976), who found LI to be unaffected by scopolamine. The latter could be due to the higher dose used by Moore et al as also in the present study, the highest dose spared LI, or could reflect species differences (Moore et al used rabbits). The fact that scopolamine acts selectively in the PE groups, and that this action is exerted in the pre-exposure stage, implies that muscarinic blockade attenuates the normal loss of attention to the stimulus occurring during nonreinforced pre-exposure (Lubow et al, 1981), in line with extensive evidence implicating the cholinergic system in attentional processes (see Blokland, 1995; Hasselmo and McGaughy, 2004; Mirza and Stolerman, 2000; Sarter et al, 2003, 1999, 2005).

Experiments 3 and 4 showed that scopolamine-induced LI disruption was reversed by the typical APD haloperidol and the atypical APD clozapine, respectively. Moreover, APDs restored disrupted LI if injected in both the pre-exposure and conditioning stages, or in the conditioning stage alone, but not in the pre-exposure stage alone. Precisely the same stage-dependent pattern of APD action is obtained for the most widely documented effect of APDs on LI, namely, LI potentiation following low number of pre-exposures that do not suffice to yield LI in no-drug controls (eg in the procedure used here, no LI is seen with 10 pre-exposures, 
but LI emerges under this condition following APD treatment; Weiner et al, 1996; Warburton et al, 1994). As functionally, pre-exposure to 40 tones under scopolamine may be equivalent to reducing the number of preexposures, restoration of LI in scopolamine-treated rats by APDs may represent an instance of APD-induced LI potentiation seen with low number of pre-exposures.

While reversal of scopolamine-induced behavioral deficits by typical and atypical APDs had been shown previously (Jones et al, 2005; Mathur et al, 1997; Shannon and Peters, 1990), the unique aspect of the present results is that scopolamine-induced LI deficit and its reversal by APDs were generated in different stages of the LI procedure taking place $24 \mathrm{~h}$ apart. Therefore, while reversal of scopolamine-induced behavioral deficits by APDs has been attributed to a direct interaction between the dopaminergic and the muscarinic cholinergic systems (eg Jones et al, 2005; Mathur et al, 1997), such an interaction cannot explain the present results. Rather, the reversal of scopolamine-induced LI disruption by APDs is likely to reflect complex interactions within the brain circuitry that modulates the expression of LI (Weiner, 2003), whereby scopolamine exerts its effects on brain substrates mediating the processing of the PE stimulus in pre-exposure that differ from but interact with brain substrates at which APDs act to potentiate LI in conditioning. Studies of the neural substrates of LI have shown that the APD-induced LI potentiation is mediated via the NAC (Joseph et al, 2000; Weiner, 2003), whereas the information on the PE stimulus is fed to the NAC from the entorhinal cortex (Jeanblanc et al, 2004; Weiner, 2003), raising the possibility that the latter is the region where muscarinic blockade acts to impair LI. While the neural substrates involved in APDinduced reversal of scopolamine-induced LI disruption remain to be investigated, the fact that scopolamine and APDs act in different stages suggests that scopolamineinduced disrupted LI may allow the detection of antipsychotic action that is independent of the mechanism of action of the propsychotic drug, opening a unique avenue for identifying agents acting through novel mechanisms.

Experiment 5 showed that scopolamine-induced LI disruption was reversed by physostigmine. This drug did not affect LI when given alone. These findings are in line with previous results using other animal models of schizophrenia. For example, physostigmine alone had no effect on PPI (Jones and Shannon, 2000b; Mach et al, 2004) or locomotor activity (Shannon and Peters, 1990; but see Mach et al, 2004), but reversed scopolamine-induced PPI disruption (Jones and Shannon, 2000b) and hyperactivity (Shannon and Peters, 1990). In contrast to its success in reversing scopolamine-induced LI disruption, physostigmine failed to restore amphetamine-induced LI disruption. This suggests that physostigmine acted to restore LI by restoring the ability to learn the irrelevance of the PE stimulus, which was impaired by scopolamine; in amphetamine-treated rats, this ability is intact (Weiner, 2003), and therefore physostigmine was inactive. While these suggestions remain to be investigated, the fact that physostigmine reversed scopolamine- but not amphetamine-induced LI disruption sets this compound apart from APDs, which reverse both deficits. The latter is inconsistent with the report that physostigmine acted like 'dopaminergic' APDs, and in particular, blocked amphetamine-induced stereotypy (Karan et al, 2000), but is in line with Stone et al's (1990) finding of low susceptibility of amphetamine-induced hyperactivity to physostigmine, because here we used a low, activity-producing dose of amphetamine. To the best of our knowledge, this is the first demonstration of distinct effects of physostigmine on scopolamine- and amphetamine-induced behavioral deficits produced in the same behavioral phenomenon.

The findings of the present study join those of other studies showing that scopolamine and other muscarinic antagonists produce psychotic-like effects in animals (eg Jones et al, 2005; Jones and Shannon, 2000a, b; Mathur et al, 1997; Shannon and Peters, 1990; Sipos et al, 1999; Ukai et al, 2004; Wu et al, 1993) and that these effects are reversed by APDs (Jones et al, 2005; Shannon and Peters, 1990) and physostigmine (Jones and Shannon, 2000b; Shannon and Peters, 1990). Disruption of LI by amphetamine and its reversal by APDs is a well-established model of positive symptoms, fortified by findings of disrupted LI in amphetamine-treated normal humans, high schizotypal individuals, and acute schizophrenia patients (see Lubow, 2005; Weiner, 2003). Therefore, disruption of LI by scopolamine and its reversal by APDs and physostigmine may provide a model of the 'positive' symptom spectrum of the antimuscarinic psychosis (anticholinergic syndrome), and by corollary, of the cholinergic aspects of positive symptoms in endogenous schizophrenia.

However, it is important to underscore in this context that in spite of their identical behavioral manifestations (disrupted LI), the 'antimuscarinic LI model' and the 'dopamine agonist LI model' are clearly distinct in several respects. First, scopolamine disrupts LI via effects exerted at the pre-exposure stage and spares LI when given in conditioning only, whereas amphetamine disrupts LI via effects exerted at the conditioning stage and spares LI if given before pre-exposure only (Gray et al, 1997; Joseph et al, 2000; McAllister, 1997; Weiner, 2003; Weiner et al, 1984, 1988). In addition to indicating that the neural substrates underlying LI disruption induced by amphetamine and scopolamine are different, the stage-based dissociation implies that the disruptions of LI induced by these two pharmacologically distinct classes of drugs cannot be attributed to a disturbance to a common psychological function. The dissociation between scopolamine- and amphetamine-induced disruption of LI is further supported by the manner in which the two abnormalities are reversed by APDs. Thus, although APDs reverse both abnormalities, in the case of amphetamine-induced LI disruption, the propsychotic and the antipsychotic actions are exerted at the same stage of the procedure and thus likely reflect a direct interaction, whereas in the case of scopolamineinduced LI disruption, the propsychotic and antipsychotic actions are generated in different stages of the procedure and thus mediated by distinct mechanisms. Third, scopolamine-induced, but not amphetamine-induced, LI disruption was reversed by physostigmine. Thus, while scopolamine-induced LI disruption can be reversed by both APDs and an AChE inhibitor, amphetamine-induced LI disruption can be reversed only by the former.

Taken together, these findings indicate that scopolamineand amphetamine-induced LI disruption represents 
different phenomena, and therefore might model different aspects of schizophrenic psychoses. Specifically, scopolamine-induced LI disruption may model muscarinic-related attentional deficits, which may be linked to cognitive impairments seen in this disorder.

The dissociation between scopolamine and amphetamine was also evident in the activity model. While amphetamine $(1 \mathrm{mg} / \mathrm{kg})$ markedly increased locomotor activity, scopolamine $(0.15$ and $0.5 \mathrm{mg} / \mathrm{kg})$ did not alter locomotor activity, supporting the notion that distinct mechanisms underlie the effects of the two psychotomimetics. Although it was suggested that scopolamine affects behavior like amphetamine by increasing striatal/accumbal DA transmission (Ichikawa et al, 2002a; Yeomans, 1995), our results in LI and locomotor activity imply that this is not the case with low doses of scopolamine.

In sum, the present study showed that low doses of scopolamine impair rats' capacity to ignore stimuli that are repeatedly presented without consequences while leaving their capacity for associative learning intact. This pattern implies that the cholinergic muscarinic system plays a role in attentional processes underlying the acquisition of LI. The latter, in turn, suggests that scopolamine-induced LI disruption may model attentional abnormalities associated with cholinergic dysfunction. In addition, the fact that scopolamine-induced LI disruption is in several respects distinct from amphetamine-induced LI disruption underscores the utility of the two deficits for modeling antimuscarinic and dopaminergic psychoses, respectively, and by extension, cholinergic and dopaminergic aspects of schizophrenic psychoses. The latter may facilitate the search for treatments that target selectively each of these abnormalities. In particular, it is of interest to determine whether specific muscarinic receptor agonists, which were shown to exhibit antipsychotic properties in the clinic, would reverse both scopolamine- and amphetamine-induced LI deficits as was shown in other animal models (Bymaster et al, 2002; Jones et al, 2005; Stanhope et al, 2001), or would show selectivity like found here for physostigmine. In addition, the capacity of cholinergic cognitive enhancers to ameliorate these deficits should be examined. Finally, it is of interest to examine whether the negative/cognitive symptom spectrum of antimuscarinic psychosis can also be modeled in the LI model.

\section{REFERENCES}

Anagnostaras SG, Maren S, Sage JR, Goodrich S, Fanselow MS (1999). Scopolamine and Pavlovian fear conditioning in rats: dose-effect analysis. Neuropsychopharmacology 21: 731-744.

Baruch I, Hemsley DR, Gray JA (1988). Differential performance of acute and chronic schizophrenics in a latent inhibition task. J Nerv Ment Dis 176: 598-606.

Blokland A (1995). Acetylcholine: a neurotransmitter for learning and memory? Brain Res Rev 21: 285-300.

Bouton ME (1993). Context, time, and memory retrieval in the interference paradigms of Pavlovian learning. Psychol Bull 114: 80-99.

Brown DV, Heller F, Barkin R (2004). Anticholinergic syndrome after anesthesia: a case report and review. Am J Ther 11: 144-153.

Bymaster FP, Felder C, Ahmed S, McKinzie D (2002). Muscarinic receptors as a target for drugs treating schizophrenia. Curr Drug Targets CNS Neurol Disord 1: 163-181.
Carlton PL, Vogel JR (1965). Studies of the amnesic properties of scopolamine. Psychon Sci 3: 261-262.

Carnicella S, Pain L, Oberling P (2005). Cholinergic effects on fear conditioning I: the degraded contingency effect is disrupted by atropine but reinstated by physostigmine. Psychopharmacology (Berl) 178: 524-532.

Clarke LA, Cassidy CW, Catalano G, Catalano MC, Carroll KM (2004). Psychosis induced by smoking cessation clinic administered anticholinergic overload. Ann Clin Psychiatry 16: 171-175.

Crook JM, Tomaskovic-Crook E, Copolov DL, Dean B (2001). Low muscarinic receptor binding in prefrontal cortex from subjects with schizophrenia: a study of Brodmann's areas 8, 9, 10, and 46 and the effects of neuroleptic drug treatment. Am J Psychiatry 158: 918-925.

Dean B, Crook JM, Opeskin K, Hill C, Keks N, Copolov DL (1996). The density of muscarinic M1 receptors is decreased in the caudate-putamen of subjects with schizophrenia. Mol Psychiatry 1: 54-58.

Della Casa V, Hofer I, Feldon J (1999). Latent inhibition in smokers $v s$ nonsmokers: interaction with number or intensity of preexposures? Pharmacol Biochem Behav 62: 353-359.

Fisher CM (1991). Visual hallucinations on eye closure associated with atropine toxicity. A neurological analysis and comparison with other visual hallucinations. Can J Neurol Sci 18: 18-27.

Friedman JI (2004). Cholinergic targets for cognitive enhancement in schizophrenia: focus on cholinesterase inhibitors and muscarinic agonists. Psychopharmacology (Berl) 174: 45-53.

Garcia-Rill E, Biedermann JA, Chambers T, Skinner RD, Mrak RE, Husain $M$ et al (1995). Mesopontine neurons in schizophrenia. Neuroscience 66: 321-335.

Gopel C, Laufer C, Marcus A (2002). Three cases of angel's trumpet tea-induced psychosis in adolescent substance abusers. Nord $J$ Psychiatry 56: 49-52.

Gosselin G, Oberling P, Di Scala G (1996). Antagonism of amphetamine-induced disruption of latent inhibition by the atypical antipsychotic olanzapine in rats. Behav Pharmacol 7: $820-826$.

Gould TJ, Collins AC, Wehner JM (2001). Nicotine enhances latent inhibition and ameliorates ethanol-induced deficits in latent inhibition. Nicotine Tob Res 3: 17-24.

Granacher RP, Baldessarini RJ (1975). Physostigmine. Its use in acute anticholinergic syndrome with antidepressant and antiparkinson drugs. Arch Gen Psychiatry 32: 375-380.

Gray JA, Joseph MH, Hemsley DR, Young AM, Warburton EC, Boulenguez P et al (1995a). The role of mesolimbic dopaminergic and retrohippocampal afferents to the nucleus accumbens in latent inhibition: implications for schizophrenia. Behav Brain Res 71: 19-31.

Gray JA, Moran PM, Grigoryan G, Peters SL, Young AM, Joseph MH (1997). Latent inhibition: the nucleus accumbens connection revisited. Behav Brain Res 88: 27-34.

Gray NS, Hemsley DR, Gray JA (1992a). Abolition of latent inhibition in acute, but not chronic, schizophrenics. Neurol Psychiatr Brain Res 1: 83-89.

Gray NS, Pickering AD, Hemsley DR, Dawling S, Gray JA (1992b). Abolition of latent inhibition by a single $5 \mathrm{mg}$ dose of damphetamine in man. Psychopharmacology (Berl) 107: 425-430.

Gray NS, Pilowsky LS, Gray JA, Kerwin RW (1995b). Latent inhibition in drug naive schizophrenics: relationship to duration of illness and dopamine D2 binding using SPET. Schizophr Res 17: 95-107.

Hasselmo ME, McGaughy J (2004). High acetylcholine levels set circuit dynamics for attention and encoding and low acetylcholine levels set dynamics for consolidation. Prog Brain Res 145: 207-231.

Holland MS (1992). Central anticholinergic syndrome in a pediatric patient following transdermal scopolamine patch placement. Nurse Anesthetists 3: 121-124. 
Hyde TM, Crook JM (2001). Cholinergic systems and schizophrenia: primary pathology or epiphenomena? J Chem Neuroanat 22: 53-63.

Ichikawa J, Chung YC, Li Z, Dai J, Meltzer HY (2002a). Cholinergic modulation of basal and amphetamine-induced dopamine release in rat medial prefrontal cortex and nucleus accumbens. Brain Res 958: 176-184.

Ichikawa J, Dai J, O'Laughlin IA, Fowler WL, Meltzer HY (2002b). Atypical, but not typical, antipsychotic drugs increase cortical acetylcholine release without an effect in the nucleus accumbens or striatum. Neuropsychopharmacology 26: 325-339.

Jeanblanc J, Peterschmitt Y, Hoeltzel A, Louilot A (2004). Influence of the entorhinal cortex on accumbal and striatal dopaminergic responses in a latent inhibition paradigm. Neuroscience 128: 187-200.

Johnstone EC, Crow TJ, Ferrier IN, Frith CD, Owens DG, Bourne RC et al (1983). Adverse effects of anticholinergic medication on positive schizophrenic symptoms. Psychol Med 13: 513-527.

Jones CK, Eberle EL, Shaw DB, McKinzie DL, Shannon HE (2005). Pharmacologic Interactions between the muscarinic cholinergic and dopaminergic systems in the modulation of prepulse inhibition in rats. J Pharmacol Exp Ther 312: 1055-1063.

Jones CK, Shannon HE (2000a). Effects of scopolamine in comparison with apomorphine and phencyclidine on prepulse inhibition in rats. Eur J Pharmacol 391: 105-112.

Jones CK, Shannon HE (2000b). Muscarinic cholinergic modulation of prepulse inhibition of the acoustic startle reflex. J Pharmacol Exp Ther 294: 1017-1023.

Joseph MH, Peters SL, Gray JA (1993). Nicotine blocks latent inhibition in rats: evidence for a critical role of increased functional activity of dopamine in the mesolimbic system at conditioning rather than pre-exposure. Psychopharmacology (Berl) 110: 187-192.

Joseph MH, Peters SL, Moran PM, Grigoryan GA, Young AM, Gray JA (2000). Modulation of latent inhibition in the rat by altered dopamine transmission in the nucleus accumbens at the time of conditioning. Neuroscience 101: 921-930.

Karan RS, Ravishankar P, Pandhi P (2000). Effect of muscarinic receptor agonists on animal models of psychosis. Methods Find Exp Clin Pharmacol 22: 169-172.

Karson CN, Garcia-Rill E, Biedermann J, Mrak RE, Husain MM, Skinner RD (1991). The brain stem reticular formation in schizophrenia. Psychiatry Res 40: 31-48.

Killcross AS, Robbins TW (1993). Differential effects of intraaccumbens and systemic amphetamine on latent inhibition using an on-baseline, within-subject conditioned suppression paradigm. Psychopharmacology (Berl) 110: 479-489.

Lo Y, Tsai SJ (1996). Trihexyphenidyl abuse in schizophrenic patient: a case report. Zhonghua Yi Xue Za Zhi (Taipei) 57: $157-160$.

Lubow R, Weiner I, Schnur P (1981). Conditioned attention theory. In: Bower G (ed). The Psychology of Learning and Motivation. Academic Press: New York.

Lubow RE (1989). Latent Inhibition and Conditioned Attention Theory. Cambridge University Press: New York.

Lubow RE (2005). Construct validity of the animal latent inhibition model of selective attention deficits in schizophrenia. Schizophr Bull 31: 139-153.

Mach M, Grubbs RD, Price WA, Paton SJ, Lucot JB (2004). Behavioral changes after acetylcholinesterase inhibition with physostigmine in mice. Pharmacol Biochem Behav 79: 533-540.

Marchlewski MB (1994). Anticholinergic syndrome. Avoiding misdiagnosis. J Psychosoc Nurs Ment Health Serv 32: 22-24.

Mathur A, Shandarin A, LaViolette SR, Parker J, Yeomans JS (1997). Locomotion and stereotypy induced by scopolamine: contributions of muscarinic receptors near the pedunculopontine tegmental nucleus. Brain Res 775: 144-155.
McAllister KH (1997). A single administration of d-amphetamine prior to stimulus pre-exposure and conditioning attenuates latent inhibition. Psychopharmacology (Berl) 130: 79-84.

Mego DM, Omori JM, Hanley JF (1988). Transdermal scopolamine as a cause of transient psychosis in two elderly patients. South Med J 81: 394-395.

Meyer U, Chang de LT, Feldon J, Yee BK (2004). Expression of the CS- and US-pre-exposure effects in the conditioned taste aversion paradigm and their abolition following systemic amphetamine treatment in C57BL6/J mice. Neuropsychopharmacology 29: 2140-2148.

Minzenberg MJ, Poole JH, Benton C, Vinogradov S (2004). Association of anticholinergic load with impairment of complex attention and memory in schizophrenia. Am J Psychiatry 161: 116-124.

Mirza NR, Stolerman IP (2000). The role of nicotinic and muscarinic acetylcholine receptors in attention. Psychopharmacology (Berl) 148: 243-250.

Moore JW, Goodell NA, Solomon PR (1976). Central cholinergic blockade by scopolamine and habituation, classical conditioning, and latent inhibition of the rabbit's nictitating membrane response. Physiol Psychol 4: 395-399.

Moran PM, Fischer TR, Hitchcock JM, Moser PC (1996). Effects of clozapine on latent inhibition in the rat. Behav Pharmacol 7: 42-48.

Naor C, Dudai Y (1996). Transient impairment of cholinergic function in the rat insular cortex disrupts the encoding of taste in conditioned taste aversion. Behav Brain Res 79: 61-67.

Nogue S, Sanz P, Munne P, de la Torre R (1991). Acute scopolamine poisoning after sniffing adulterated cocaine. Drug Alcohol Depend 27: 115-116.

Perry EK, Perry RH (1995). Acetylcholine and hallucinations: disease-related compared to drug-induced alterations in human consciousness. Brain Cogn 28: 240-258.

Perry PJ, Wilding DC, Juhl RP (1978). Anticholinergic psychosis. Am J Hosp Pharm 35: 725-728.

Raedler TJ, Knable MB, Jones DW, Urbina RA, Gorey JG, Lee KS et al (2003). In vivo determination of muscarinic acetylcholine receptor availability in schizophrenia. Am J Psychiatry 160: 118-127.

Rascle C, Mazas O, Vaiva G, Tournant M, Raybois O, Goudemand $\mathrm{M}$ et al (2001). Clinical features of latent inhibition in schizophrenia. Schizophr Res 51: 149-161.

Rochford J, Sen AP, Quirion R (1996). Effect of nicotine and nicotinic receptor agonists on latent inhibition in the rat. J Pharmacol Exp Ther 277: 1267-1275.

Salgado JV, Hetem LA, Vidal M, Graeff FG, Danion JM, Sandner G (2000). Reduction of latent inhibition by D-amphetamine in a conditioned suppression paradigm in humans. Behav Brain Res 117: 61-67.

Sarter M, Bruno JP, Givens B (2003). Attentional functions of cortical cholinergic inputs: what does it mean for learning and memory? Neurobiol Learn Mem 80: 245-256.

Sarter M, Bruno JP, Turchi J (1999). Basal forebrain afferent projections modulating cortical acetylcholine, attention, and implications for neuropsychiatric disorders. Ann NY Acad Sci 877: $368-382$.

Sarter M, Nelson CL, Bruno JP (2005). Cortical cholinergic transmission and cortical information processing in schizophrenia. Schizophr Bull 31: 117-138.

Shadach E, Feldon J, Weiner I (1999). Clozapine-induced potentiation of latent inhibition is due to its action in the conditioning stage: implications for the mechanism of action of antipsychotic drugs. Int J Neuropsychopharmcol 2: 283-291.

Shadach E, Gaisler I, Schiller D, Weiner I (2000). The latent inhibition model dissociates between clozapine, haloperidol, and ritanserin. Neuropsychopharmacology 23: 151-161.

Shannon HE, Peters SC (1990). A comparison of the effects of cholinergic and dopaminergic agents on scopolamine-induced hyperactivity in mice. J Pharmacol Exp Ther 255: 549-553. 
Singh MM, Kay SR (1975). Therapeutic reversal with benxtropine in schizophrenics. Practical and theoretical significance. J Nerv Ment Dis 160: 258-266.

Singh MM, Kay SR (1979). Therapeutic antagonism between anticholinergic antiparkinsonism agents and neuroleptics in schizophrenia. Implications for a neuropharmacological model. Neuropsychobiology 5: 74-86.

Sipos ML, Burchnell V, Galbicka G (1999). Dose-response curves and time-course effects of selected anticholinergics on locomotor activity in rats. Psychopharmacology (Berl) 147: 250-256.

Snyder SH (1973). Amphetamine psychosis: a 'model' schizophrenia mediated by catecholamines. Am J Psychiatry 130: 61-67.

Stanhope KJ, Mirza NR, Bickerdike MJ, Bright JL, Harrington NR, Hesselink MB et al (2001). The muscarinic receptor agonist xanomeline has an antipsychotic-like profile in the rat. J Pharmacol Exp Ther 299: 782-792.

Stone WS, Rudd RJ, Gold PE (1990). Glucose and physostigmine effects on morphine- and amphetamine-induced increases in locomotor activity in mice. Behav Neural Biol 54: 146-155.

Swerdlow NR, Stephany N, Wasserman LC, Talledo J, Sharp R, Auerbach PP (2003). Dopamine agonists disrupt visual latent inhibition in normal males using a within-subject paradigm. Psychopharmacology (Berl) 169: 314-320.

Swerdlow NR, Stephany N, Wasserman LC, Talledo J, Sharp R, Minassian A et al (2005). Intact visual latent inhibition in schizophrenia patients in a within-subject paradigm. Schizophr Res 72: 169-183.

Tandon R (1999). Cholinergic aspects of schizophrenia. $\mathrm{Br} \mathrm{J}$ Psychiatry 174(Suppl 37): 7-11.

Tandon R, DeQuardo JR, Goodson J, Mann NA, Greden JF (1992). Effect of anticholinergics on positive and negative symptoms in schizophrenia. Psychopharmacol Bull 28: 297-302.

Tandon R, Mann NA, Eisner WH, Coppard N (1990). Effect of anticholinergic medication on positive and negative symptoms in medication-free schizophrenic patients. Psychiatry Res 31: 235-241.

Thornton JC, Dawe S, Lee C, Capstick C, Corr PJ, Cotter P et al (1996). Effects of nicotine and amphetamine on latent inhibition in human subjects. Psychopharmacology (Berl) 127: 164-173.

Ukai M, Okuda A, Mamiya T (2004). Effects of anticholinergic drugs selective for muscarinic receptor subtypes on prepulse inhibition in mice. Eur J Pharmacol 492: 183-187.

Wang H, Ng K, Hayes D, Gao X, Forster G, Blaha C et al (2004). Decreased amphetamine-induced locomotion and improved latent inhibition in mice mutant for the M5 muscarinic receptor gene found in the human $15 \mathrm{q}$ schizophrenia region. Neuropsychopharmacology 29: 2126-2139.
Warburton EC, Joseph MH, Feldon J, Weiner I, Gray JA (1994). Antagonism of amphetamine-induced disruption of latent inhibition in rats by haloperidol and ondansetron: implications for a possible antipsychotic action of ondansetron. Psychopharmacology (Berl) 114: 657-664.

Weiner DM, Meltzer HY, Veinbergs I, Donohue EM, Spalding TA, Smith TT et al (2004). The role of M1 muscarinic receptor agonism of $\mathrm{N}$-desmethylclozapine in the unique clinical effects of clozapine. Psychopharmacology (Berl) 177: 207-216.

Weiner I (1990). Neural substrates of latent inhibition: the switching model. Psychol Bull 108: 442-461.

Weiner I (2000). The latent inhibition model of schizophrenia. In: Myslobodsky MS, Weiner I (eds). Contemporary Issues in Modeling Psychopathology. Kluwer: Boston. pp 197-230.

Weiner I (2003). The 'two-headed' latent inhibition model of schizophrenia: modeling positive and negative symptoms and their treatment. Psychopharmacology (Berl) 169: 257-297.

Weiner I, Feldon J (1997). The switching model of latent inhibition: an update of neural substrates. Behav Brain Res 88: 11-25.

Weiner I, Feldon J, Katz Y (1987). Facilitation of the expression but not the acquisition of latent inhibition by haloperidol in rats. Pharmacol Biochem Behav 26: 241-246.

Weiner I, Lubow RE, Feldon J (1984). Abolition of the expression but not the acquisition of latent inhibition by chronic amphetamine in rats. Psychopharmacology (Berl) 83: 194-199.

Weiner I, Lubow RE, Feldon J (1988). Disruption of latent inhibition by acute administration of low doses of amphetamine. Pharmacol Biochem Behav 30: 871-878.

Weiner I, Shadach E, Barkai R, Feldon J (1997). Haloperidol- and clozapine-induced enhancement of latent inhibition with extended conditioning: implications for the mechanism of action of neuroleptic drugs. Neuropsychopharmacology 16: 42-50.

Weiner I, Shadach E, Tarrasch R, Kidron R, Feldon J (1996). The latent inhibition model of schizophrenia: further validation using the atypical neuroleptic, clozapine. Biol Psychiatry 40: 834-843.

Wilkinson JA (1987). Side effects of transdermal scopolamine. J Emerg Med 5: 389-392.

Wu MF, Jenden DJ, Fairchild MD, Siegel JM (1993). Cholinergic mechanisms in startle and prepulse inhibition: effects of the false cholinergic precursor $\mathrm{N}$-aminodeanol. Behav Neurosci 107: 306-316.

Yeomans JS (1995). Role of tegmental cholinergic neurons in dopaminergic activation, antimuscarinic psychosis and schizophrenia. Neuropsychopharmacology 12: 3-16.

Zavitsanou K, Katsifis A, Yu Y, Huang XF (2005). M2/M4 muscarinic receptor binding in the anterior cingulate cortex in schizophrenia and mood disorders. Brain Res Bull 65: 397-403. 